LBNL-50850

\title{
Development and Evaluation of a Personal Particulate Organic and Mass Sampler
}

Yanbo Pang* (1), Lara A. Gundel (2), Timothy Larson (3), Dennis Finn (1), L.-J. Sally Liu (4), and Candis S. Claiborn** (1)

In Press, October 2002

Environmental Science and Technology

(1) Department of Civil and Environmental Engineering, Washington State University, Pullman, Washington 99164-2910.

(2) Environmental Energy Technologies Division, Ernest Orlando Lawrence Berkeley National Laboratory, University of California, Berkeley, California 94720, and

(3) Department of Civil and Environmental Engineering, and the (4) Department of Environmental Health, University of Washington, Seattle, Washington 98195

\footnotetext{
* Currently at Environmental Energy Technologies Division, Ernest Orlando Lawrence Berkeley National Laboratory, University of California, Berkeley, CA 94720

** Author to whom correspondence should be addressed; contact information: Candis Claiborn, Associate Professor, Department of Civil and Environmental Engineering, Sloan 101, Washington State University, Pullman, WA 99164-2910. ph (509) 335-5055, fax (509) 335-7632, claiborn@wsu.edu
}

Submitted to ES\&T May 8, 2002; 


\begin{abstract}
Accurate measurement of personal exposure to particulate matter and its constituents requires samplers that are accurate, compact, lightweight, inexpensive, and convenient to use. The Personal Particulate Organic and Mass Sampler (PPOMS) has been developed to meet these criteria. The PPOMS uses activated carbon-impregnated foam as a combined 2.5- $\mu \mathrm{m}$ size-selective inlet and denuder for assessment of fine particle mass and organic carbon. Proof of the PPOMS concept has been established by comparing mass and organic carbon in particles collected with collocated samplers in Seattle, at a central outdoor site, and in residences. Daily particulate mass concentrations averaged 10.0 \pm 5.2 ,

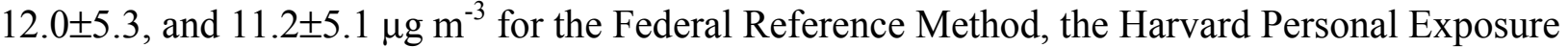
Monitor, and the PPOMS, respectively, for 10 24-h sampling periods. During a series of $\mathrm{PM}_{2.5}$ indoor organic carbon (OC) measurements from single quartz filters, the apparent indoor OC averaged 7.7 \pm 0.8 $\mu \mathrm{g}$ of $\mathrm{C} \mathrm{m}^{-3}$, which was close to the indoor $\mathrm{PM}_{2.5}$ mass from collocated Teflon filters $(7.3 \pm 2.3 \mu \mathrm{g}$ of $\mathrm{C}$ $\mathrm{m}^{-3}$ ), indicating the presence of a large positive OC artifact. In collocated measurements, the PPOMS eliminated this artifact just as well as the Integrated Gas and Particle Sampler that incorporated a macroreticular polystyrene- divinylbenzene (XAD-4) resin-coated denuder, yielding OC concentrations of $2.5 \pm 0.4$ and $2.4 \pm 1.0 \mu \mathrm{g} \mathrm{C} \mathrm{m}^{-3}$, respectively. Thermal analysis for OC indicated that the indoor positive artifact was due to adsorption of gas-phase semivolatile organic compounds SVOC. This study shows that the PPOMS design provides a $2.5-\mu \mathrm{m}$ size-selective inlet that also prevents the adsorption of gas-phase SVOC onto quartz filters, thus eliminating the filter positive artifact. The PPOMS meets a significant current challenge for indoor and personal sampling of particulate organic carbon. The PPOMS design can also simplify accurate ambient sampling for $\mathrm{PM}_{2.5}$.
\end{abstract}




\section{INTRODUCTION}

Accurate measurement of personal exposure to particulate matter (PM) and its constituents contributes not only to understanding the health effects associated with exposure to aerosols but also to identification of the sources of particulate matter to which humans are exposed. Although it is widely recognized that some particulate organic constituents are mutagenic, $(1,2)$, little effort has been made to study the toxicological effects of atmospheric organic PM due to the complexity of measuring atmospheric organic PM. The National Research Council (3) has identified measuring personal exposure to particulate matter and quantifying its chemical composition as high priority research needs. Saldiva and colleagues (4) recently provided evidence relating lung inflammation to particle composition in concentrated ambient air particles including organics.

Many particulate organic compounds are labile or semivolatile species. This characteristic is responsible for one of the biggest current challenges for accurate measurement of personal exposure to ambient aerosols: how to deal with the artifacts that can occur during sampling for particulate organic compounds. A "positive" sampling artifact (5-8) results from the adsorption of vapor-phase semivolatile organic compounds (SVOC) onto the filter that collects particles, or even onto the particles. A "negative" sampling artifact (9-13) occurs when SVOC desorb or volatilize from the particles. High, net positive, sampling artifacts have been observed during indoor particulate organic carbon (OC) sampling using quartz filters (14-15). It is not yet known whether a similar, net positive, sampling artifact occurs during the measurement of personal exposure to particulate organic carbon; however, one is expected because positive artifacts have been observed in both outdoor and indoor sampling (5$8,14,15)$. Such measurement artifacts hinder not only the characterization of indoor and personal exposures to various constituents of PM but also the source apportionment efforts in identifying sources that contribute to personal PM exposures and health effects. We know of no existing artifact-free personal particulate organic sampling device, yet understanding health effects requires an improved technique for accurate characterization of personal exposure to particulate organic material (POM). The focus of this study is elimination of the positive artifact.

During the last two decades, diffusion denuder techniques have been introduced to eliminate artifacts during fixed-location ambient particulate sampling. Two successful denuder systems for the removal of gas-phase organic compounds are the Brigham Young University Organic Sampling System $(B O S S)(16)$ and the Integrated Organic Vapor-Particle Sampler (IOVPS)(17) and its larger versions, the Integrated Organic Gas and Particulate Sampler (IOGAPS) $(18,19)$. The BOSS denuder is based on Fitz' parallel-plate diffusion battery design (20) and has parallel strips of charcoal impregnated filter paper. The IOVPS and IOGAPS use denuders that are coated with very finely ground XAD-4, an extractable, porous, macroreticular, nonpolar, polystyrene-divinylbenzene resin, with high surface area $\left(725 \mathrm{~m}^{2} \mathrm{~g}^{-1}\right)$ for adsorption of a wide range of SVOC. Both types of samplers include postfilter sorbents (sorbent resin beds, carbon- or XAD-impregnated filters) for assessment of negative artifacts caused by evaporation of organic compounds from the particles during sampling. While these designs minimize artifacts, both of these systems are too large for personal exposure assessment. The denuder sections alone are at least $20 \mathrm{~cm}$ long.

A sampler to measure personal $\mathrm{PM}_{2.5}$ should have high removal efficiency for gas-phase organic compounds, and it should be accurate, compact, lightweight, inexpensive, and convenient to use. Some of these criteria are met using porous foam as a size,selective inlet. Kenny $(21,22)$ reported the use of porous foam inlets for personal sampling of inhalable, thoracic, and respirable dust, as well as $\mathrm{PM}_{2.5}$, $\mathrm{PM}_{10}$, and bioaerosols. Here we have combined porous foam and denuder technology to develop a

Submitted to ES\&T May 8, 2002; 
personal sampler with an inlet that provides both size selectivity and gas denuding. The new Personal Particulate Organic and Mass Sampler (PPOMS) uses activated carbon-impregnated foam as a combined size-selective and denuder inlet. This report describes the design and evaluation of the PPOMS, along with results of pilot-scale field testing.

\section{EXPERIMENTAL METHODS}

Personal Particulate Organic and Mass Sampler. The (PPOMS)
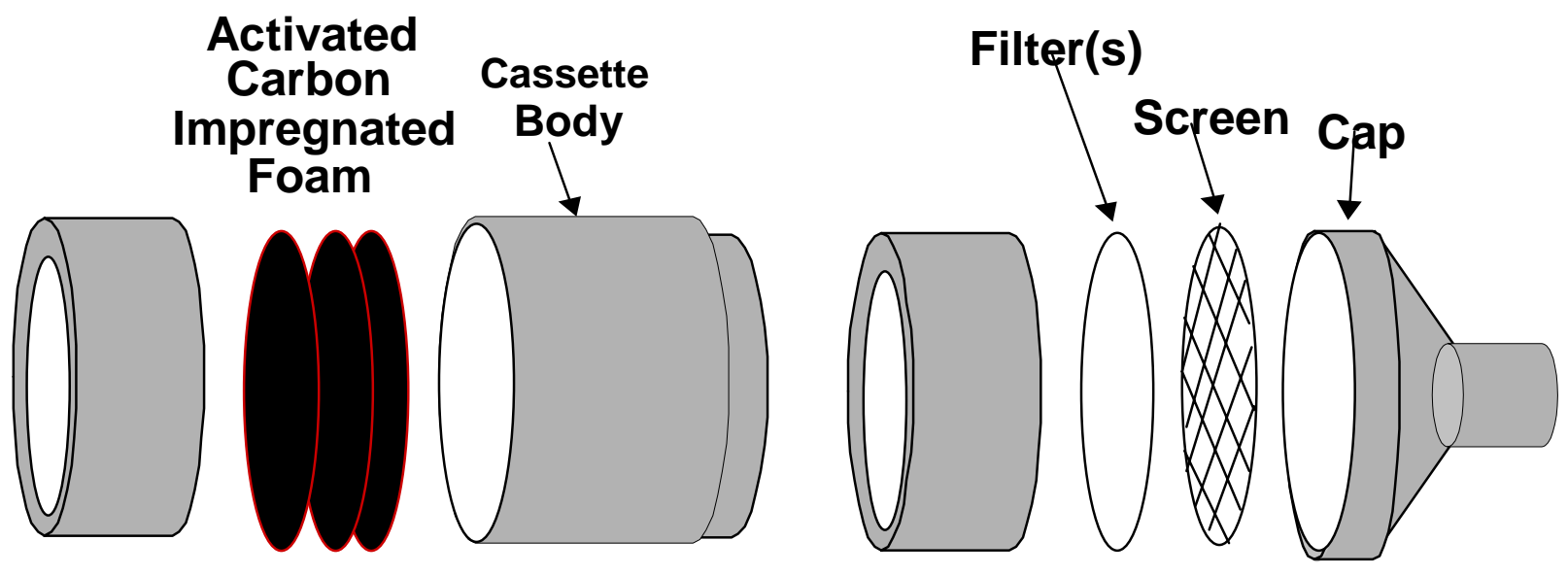

Figure 1. Schematic diagram of the PPOMS.

The PPOMS (Figure 1) was assembled in a three-piece cassette of black carbon-filled polypropylene (25-mm diameter, Cole-Parmer Inc., Part No. 10380-00). Foam disks were placed in the cassette body, between short sections of Tygon 3630 tubing. The gap between the air inlet and the foam $(0.5-2 \mathrm{~cm})$ acted as a flow straightener to distribute the incoming air evenly across the foam. Particles were collected downstream on a prefired quartz filter supported on a stainless steel screen (URG Corp., Chapel Hill, NC). The second piece of tubing created a spacer of $\sim 0.5 \mathrm{~cm}$ between the foam and filter. The filter and screen were held in place by press fit with the cassette body.

Activated carbon-impregnated foam (ACF) is composed of fine activated carbon particles $(<10$ $\mu \mathrm{m}$ diameter) that are incorporated uniformly into open-cell polyurethane foam at the time the foam is formulated. Moderate heating is used to bind the activated carbon particles to the PUF. ACF can be $60 \% \mathrm{AC}$ by weight, according to the manufacturers' information. A basic descriptor of the geometry of foams is "pores per inch" ppi, which defines the number of pores per linear inch. Two types of ACF were used during the development of the PPOMS. The first had $110 \mathrm{ppi}$ and was provided by Lewcott Corp. in a 1.5-mm-thick sheet (ACF-F110PPI-0.065-150). As discussed below, several disks of foam were packed together to achieve the $2.5-\mu \mathrm{m}$ size cut. Later in the study, for assessment of the quartz filter artifact, the $110 \mathrm{ppi}$ foam was supplemented by a second type of foam, 20 ppi ACF from Macauto Industrial Co. (ACS-CPS2 05/w350). This was a precautionary step to ensure adequate vapor adsorption capacity, because the 110 ppi carbon foam had been stored for more than 6 months before the second phase of experiments began. 


\section{Sample Collection and Analysis.}

All experiments were conducted in greater Seattle, WA, between November 2000 and May 2001. Outdoor sampling for $\mathrm{PM}_{2.5}$ mass was conducted at the Beacon Hill EPA Air Quality and Particulate Speciation Monitoring site, operated by the Washington Department of Ecology. The PPOMS was collocated with two Federal Reference Method (FRM) samplers (Rupprecht and Patashnick, Albany, N $\mathrm{Y}$ ) and a Harvard $\mathrm{PM}_{2.5}$ Personal Environmental Monitor (HPEM, Harvard School of Public Health, Boston, MA). The HPEM operated at $4 \mathrm{~L} \mathrm{~min}^{-1}$ and collected particles on Teflon filters (37 mm, Teflo 2- $\mu \mathrm{m}$ pore size, Catalog No. 225-1709, SKC, Inc., Eighty Four, PA). The HPEM had a 50\% cut point of $2.5 \mu \mathrm{m}(23)$ at $4 \mathrm{~L} \mathrm{~min}^{-1}$. HPEM and PPOMS samples were collected for $24 \mathrm{~h}$, starting at 0:00 PST.

The purpose of the measurements at Beacon Hill was optimization of foam thickness in the PPOMS, for best mass match with the FRM PM 2.5 . These experiments were conducted in two stages: first, from November 28 to December 6, 2000, during which 4.5-, 9-and 12-mm 110 ppi thicknesses of ACF were used, and from May 7 to May 25, 2001, when a second set of five PPOMS samples was collected using a modified configuration (12-mm thickness of 110 ppi ACF plus 40-mm of 20 ppi ACF).

Indoor sampling of particulate carbon was conducted to assess the effectiveness of the PPOMS in minimizing positive sampling artifacts. These measurements were coordinated with ongoing exposure assessments by the Northwest Particulate Matter and Health Effects Center, and they were conducted at subjects' houses in May, 2001. Environmental tobacco smoke (ETS) was not present at any time in the residences that we sampled. One PPOMS (with 12-mm 110 ppi ACF plus 40-mm 20 ppi ACF), one Integrated Organic Gas and Particle Sampler, and one Harvard Impactor $\left(\mathrm{HI}_{2.5}\right)$ were collocated inside two houses in suburban Seattle, specifically in Lynnwood, WA, from May 7 to May 10, 2001, and in Mountlake Terrace, from May 15 to 25, 2001. Five sets of samples were collected at each house. The $\mathrm{HI}_{2.5}$ (Air Diagnostics and Engineering, Inc., Naples, ME) had one impactor stage and one filter stage that held two 37-mm quartz filters in series. The filters were separated by a polyester drain disk (Catalog No. 230800, Whatman, Inc., Fairfield, NJ). Particles of aerodynamic diameter greater than 2.5 $\mu \mathrm{m}$ were removed by the impaction plate that had a light film of silicone oil, and smaller particles were collected on the first filter. Measurements obtained from this first filter corresponded to those from the single filter of conventional samplers (hereafter referred to as the single-filter method). The first filter was subject to positive artifacts from vapor phase adsorption onto the quartz filter material. The second filter was used to estimate the quartz filter positive artifact via the double-filter method $(6)$ in which the $\mathrm{PM}_{2.5}$ organic carbon concentration was estimated by subtracting the $\mathrm{OC}$ on the second filter from that on the first filter. (Turpin recommended ( 6 ) better artifact OC estimation from a quartz filter that follows a Teflon filter. This requires using another collocated sampler.)

The IOGAPS (URG) operated at $16.7 \mathrm{~L} \mathrm{~min}^{-1}$. The sampler included a cyclone inlet with a 2.5$\mu \mathrm{m}$ aerodynamic diameter cut point. After the cyclone, the air passed through a resin-coated (24), sandblasted glass denuder ( 8 channels, $5.1-\mathrm{cm}$ o.d., 27-cm coated length) that collected vapor-phase semivolatile organic compounds. Following the diffusion denuder, particles were collected on a quartz filter. The IOGAPS uses LBNL's fine sorbent coating for the denuders and quartz filter. The coating is prepared from commercial XAD-4 resin beads that have been milled to submicrometer size. One XADcoated quartz (XQ) filter followed, to collect semivolatile organic compounds lost from particles, for gas/particle partitioning studies that are not discussed here. XQ filters were not used with the PPOMS, HPEM, or HI2.5 samplers.

Submitted to ES\&T May 8, 2002; 


\section{Quality control and assurance.}

The "on" and "off" flow rates for the $\mathrm{HI}_{2.5}$, HPEM, and PPOMS (all $4 \mathrm{~L} \mathrm{~min}^{-1}$ ) were monitored daily in the field with a flowmeter (N092-04, Cole Parmer Inc.) that had been calibrated against a dry gas meter. All measurements had flow rates within $5 \%$ of $4 \mathrm{~L} \mathrm{~min}^{-1}$. No data points had to be rejected because of out-of-tolerance flow rates. If they had occurred, each data point would be flagged and evaluated for rejection from the data set.

Teflon filters had been conditioned at $22^{\circ} \mathrm{C}$ and $33 \% \mathrm{RH}$ for at least $24 \mathrm{~h}$ before weighing with an ultramicrobalance (Mettler Toledo, Model UMT2) in an environmental chamber (25). Filter mass measurements were reproducible within $\pm 1.8 \mu \mathrm{g}$, based on repeated weighing of the same filters. Teflon filter field blanks were collected for both the HPEM (one blank per day, corresponding to one blank per seven samples, averaging $-0.5 \mu \mathrm{g} \mathrm{m}^{-3}$ for this study) and the PPOMS (one blank per five samples, averaging $-0.5 \mu \mathrm{g} \mathrm{m}^{-3}$ ). The mass concentrations were not corrected for blanks, to be consistent with the EPA method for the FRM. Quartz filters were prefired to $800^{\circ} \mathrm{C}$ and kept sealed before use. Exposed filters were sealed in polycarbonate Petri dishes and frozen until analysis.

\section{Carbon analysis.}

After exposure, all quartz filter samples were analyzed for OC and EC by thermal optical transmission (TOT) at Washington State University using a modified version of the NIOSH method (26). This method consists of two heating phases, the first using oxygen-free helium carrier gas, for OC, and the second with helium carrier gas containing $2 \%$ oxygen for electrical carbon (EC). In the first phase, filter-collected particles are heated sequentially in helium to a series of temperature set points to volatilize organic compounds in groups that correspond to their volatility. The evolved gases are oxidized over $\mathrm{MnO}_{2}$ to $\mathrm{CO}_{2}$ before conversion to $\mathrm{CH}_{4}$ and detection by flame ionization detection (FID). During the second phase, the sample is cooled somewhat and oxygen is added to the carrier gas. The remaining carbonaceous material (black or elemental carbon) is directly oxidized to $\mathrm{CO}_{2}$ and subsequently converted to $\mathrm{CH}_{4}$. The gas chromatographic FID method is specific for carbon.

In this study, the sample was heated to the following temperature set points and held for the time indicated in parentheses: $250^{\circ} \mathrm{C}(60 \mathrm{~s}), 500^{\circ} \mathrm{C}(60 \mathrm{~s}), 630^{\circ} \mathrm{C}(60 \mathrm{~s})$, and $870{ }^{\circ} \mathrm{C}(90 \mathrm{~s})$ in pure $\mathrm{He}$, followed by $30 \mathrm{~s}$ during which the heater was off, and then $500(10 \mathrm{~s}), 600{ }^{\circ} \mathrm{C}(20 \mathrm{~s}), 670{ }^{\circ} \mathrm{C}(20 \mathrm{~s}), 740$ ${ }^{\circ} \mathrm{C}(20 \mathrm{~s}), 810^{\circ} \mathrm{C}(20 \mathrm{~s}), 860{ }^{\circ} \mathrm{C}(20 \mathrm{~s})$, and $920^{\circ} \mathrm{C}(120 \mathrm{~s})$ in a $2 \% \mathrm{O}_{2}$ in He. Organic carbon was reported in five fractions based upon the first four temperature steps (i.e., pure He environment phase), with the most volatile and lowest molecular weight compounds volatilizing first. OC1 corresponded to peak $1\left(250{ }^{\circ} \mathrm{C}\right)$, OC2 to peak $2\left(500^{\circ} \mathrm{C}\right)$, OC 3 to peak $3\left(630^{\circ} \mathrm{C}\right)$, OC4 to peak $4\left(870{ }^{\circ} \mathrm{C}\right)$, and $\mathrm{OC} 5$ to pyrolyzed $\mathrm{OC}$, defined as the carbon evolved from the filter after initial introduction of $\mathrm{O}_{2}$ and before the filter returned to its initial transmissivity as determined from the optical transmission record (26). The total OC was taken as the sum of these five fractions, and elemental carbon was the difference between the carbon evolved in the presence of $\mathrm{O}_{2}$ and the pyrolized carbon (OC5). All OC concentrations were corrected for filter blanks (Table 1).

Precision of the total carbon from the TOT analysis corresponded to $\sim \pm 0.5 \mu \mathrm{g} \mathrm{m}^{-3}$, based on replicate analyses. There are no currently accepted organic standards for the accuracy or precision of the OC, its OC fractions, or EC, except that total particulate $\mathrm{C}$ should be the sum of OC, EC, and carbonate carbon, (if present). Use of blanks may overestimate the precision of the TOT method. 
Table 1. Summary of Blank Values (Means and Standard Deviations) for Carbon Analyses on Filter Samples Collected Using the PPOMS, IOGAPS, and HI2.5 Double-Filter Methods.

\begin{tabular}{lllll}
\hline Parameter & Temperature Step & PPOMS $^{\mathrm{a}}$ & IOGAPS $^{\mathrm{a}}$ & $\mathrm{HI}_{2.5}{ }^{\mathrm{b}}$ \\
\hline OC1 & $250^{\circ} \mathrm{C}$ & $0.09 \pm 0.01$ & $0.01 \pm 0.01$ & $0.53 \pm 0.23$ \\
OC2 & $500^{\circ} \mathrm{C}$ & $0.17 \pm 0.04$ & $0.06 \pm 0.03$ & $0.82 \pm 0.32$ \\
OC3 & $650^{\circ} \mathrm{C}$ & $0.06 \pm 0.03$ & $0.02 \pm 0.02$ & $0.37 \pm 0.15$ \\
OC4 & $850^{\circ} \mathrm{C}$ & $0.04 \pm 0.02$ & $0.02 \pm 0.03$ & $0.49 \pm 0.24$ \\
OC5 & Pyrolytic OC & $0.04 \pm 0.01$ & $0.02 \pm 0.03$ & $0.01 \pm 0.26$ \\
OC & Sum of OC1 - OC5 & $0.39 \pm 0.09$ & $0.13 \pm 0.08$ & $2.22 \pm 0.94$ \\
EC & & $0.00 \pm 0.00$ & $0.00 \pm 0.00$ & $0.13 \pm 0.30$ \\
\hline
\end{tabular}

${ }^{a}$ Laboratory blanks

${ }^{\mathrm{b}}$ Field blanks

\section{RESULTS AND DISCUSSION}

\section{Foam Thickness Selection}

The use of foam as a size-selective inlet has been the subject of several experimental and theoretical studies $(21,22,27,28)$. These efforts investigated factors that affect the penetration of particles through foam, with a lot of attention to pore density, foam thickness, and face velocity, as well as consideration of the advantages and disadvantages of foam for size selection. Particle penetration through foams depends on face velocity (the ratio of the flow rate to the cross-sectional area perpendicular to the flow direction), as well as foam thickness and pore density, as described by Vincent et al. (27). They also presented a semiempirical equation that predicts particle penetration based on face velocity, foam porosity, and thickness. For example, 100 ppi foam has smaller pores than 20 ppi foam and, at a given face velocity, traps smaller particles than 20 ppi foam. Chen (28) found that solid particles larger than $6 \mu \mathrm{m}$ experienced some small bounce effects for noncoated foam when solid particles were used to evaluate aerosol penetration. Chen also indicated that pore clogging by particles was small.

A commercially available sampler (SKC) has a $\mathrm{PM}_{2.5}$ foam inlet based on Kenny's design $(21,22)$ intended for industrial hygiene monitoring. Because the extensive body of previous work on particle penetration used polyurethane foam $(21,22,28)$, this study did not repeat the earlier efforts, but instead concentrated on the use of activated carbon-impregnated foam not only as a size-selective inlet but also as a denuder. 


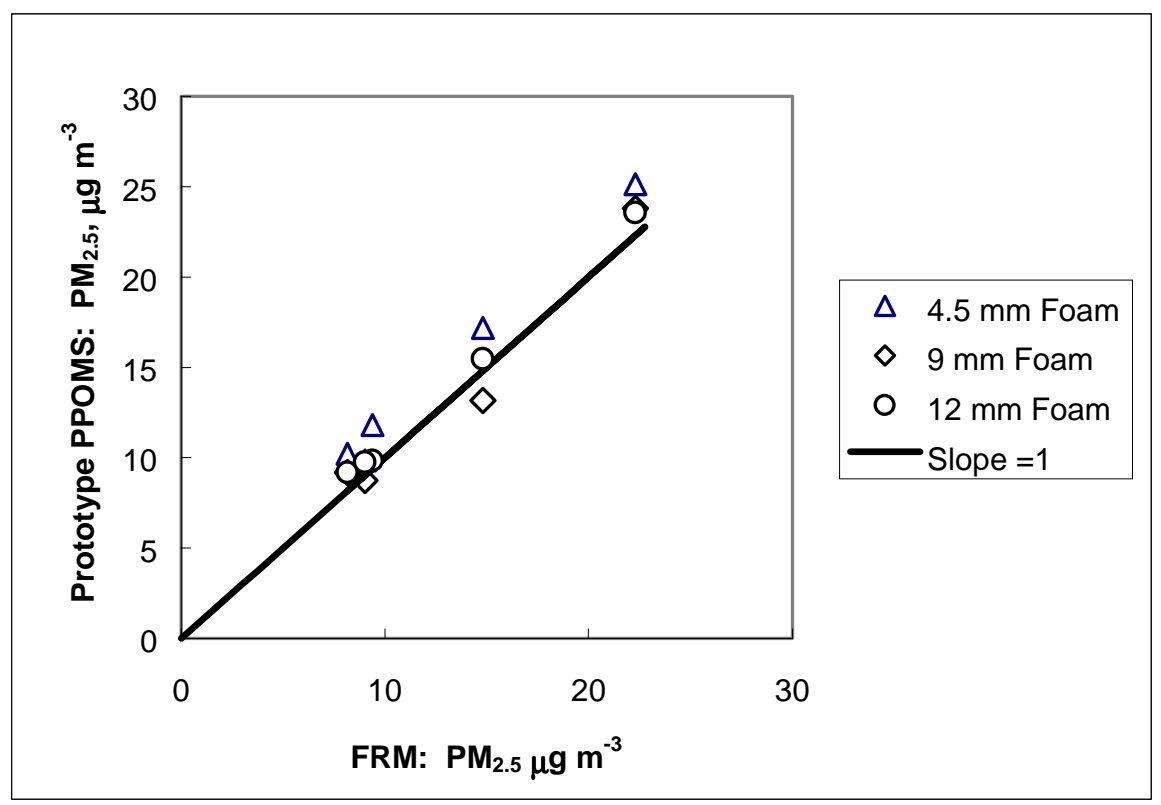

Figure 2. $\mathrm{PM}_{2.5}$ mass determined from prototype PPOMS with different thickness of foam vs $\mathrm{PM}_{2.5}$ mass determined from the FRM.

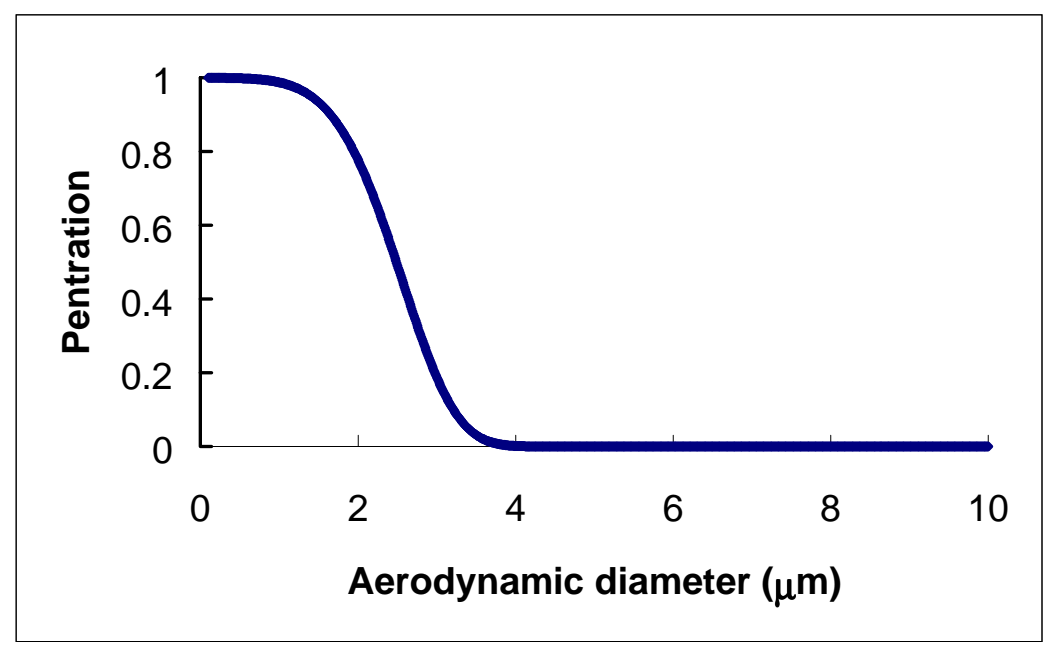

Figure 3. Predicted penetration of particles through the denuder inlet of POMS using the model of Vincent et al. (24).

To our knowledge, this is the first time that ACF has been used as the size-selective inlet. Variation of the foam thickness was used to tailor the particle size cut of the PPOMS because the foam thickness could easily be changed, whereas the requirements for personal sampling dictated the low flow rate, small filter area, and thus the filter face velocity. Vincent's empirical model (27) was used to select the thickness range for the first prototypes: $4.5,9$, and $12 \mathrm{~mm}$ were selected because their predicted particle cut points for 110 ppi foam are $3.06,2.64$, and $2.48 \mu \mathrm{m}$, respectively. Some shift to lower cut points might be observed if the manufacturer's description did not account for any lowering of the apparent pore size by the presence of small carbon particles.

Submitted to ES\&T May 8, 2002; 
Figure 2 shows the ambient PM mass concentrations obtained at an outdoor monitoring site, Beacon Hill. The PPOMS was deployed with the three foam thicknesses mentioned earlier, and data from each configuration were compared with the $\mathrm{PM}_{2.5}$ data from the collocated FRM samplers. The PPOMS with 12-mm thickness of 110 ppi ACF showed the best agreement with FRM PM 2.5 mass, although there was very little difference across this foam thickness range. The apparent lack of sensitivity to thickness is consistent with the minimum observed between 2 and $4 \mu \mathrm{g}$ in the typical ambient PM bimodal particle mass size distribution. Figure 2 also suggests that the impregnated activated carbon powder did not significantly influence the particle cut point.

Subsequent PPOMS were constructed with 12-mm thickness, 110 ppi ACF. The cut point diameter $\left(D_{50}\right)$ of the PPOMS is $2.5 \mu \mathrm{m}$, based on the predictions of the Vincent model (27) for 110 ppi with the sampler geometry and flow rate described above and agreement with the FRM $\mathrm{PM}_{2.5}$ data. The same cut point is expected in the PPOMS to which additional foam (20 ppi) had been added for renewal of SVOC removal capacity.

Table 2. Comparison of PM2.5 mass ( $\mu \mathrm{g} / \mathrm{m} 3)$ for FRM, HPEM and PPOMS

\begin{tabular}{lccc} 
& FRM & HPEM & PPOMS \\
\hline $\mathrm{n}$ & 10 & 8 & 10 \\
average & 10.0 & 12.0 & 11.2 \\
$\mathrm{SD}$ & 5.2 & 5.3 & 5.1 \\
\hline
\end{tabular}

The additional foam had much larger pores, allowing $\mathrm{PM}_{2.5}$ to pass freely. Vincent's equation (27) predicts that the $50 \%$ particle cut point for $12-\mathrm{mm} 110$ ppi foam with our PPOMS design is 2.48 $\mu \mathrm{m}$. After adding 40-mm 20 ppi in PPOMS, the predicted $50 \%$ cut point changes to $2.47 \mu \mathrm{m}$, an insignificant change.

\section{Comparison of PPOMS and HPEM for PM$_{2.5}$ Mass.}

To establish proof of concept that the PPOMS can accurately measure $\mathrm{PM}_{2.5}$ mass for personal exposure assessment, the PPOMS and the $\operatorname{HPEM}(29,30)$, a personal exposure sampler for $\mathrm{PM}_{2.5}$ mass, were collocated at Beacon Hill, Seattle WA, with the FRM as the standard method. Our main purpose was not evaluating HPEMs by comparison to FRMs, but establishing that the PPOMS provides data comparable to the HPEM and FRM. We tested two configurations of the PPOMS: one with 12-mm thickness of 110 ppi ACF and the other with 12-mm thickness of 110 ppi ACF plus $40-\mathrm{mm}$ thickness of 20 ppi ACF.

The HPEM and PPOMS both used Teflon filters and the observed $\mathrm{PM}_{2.5}$ mass concentrations correlated well with each other $\left(R^{2}=0.84\right.$, Slope $=0.88$, and intercept $\left.=2.42\right)$. The nonparametric Wilcoxon rank sum test indicated no significant difference between $\mathrm{PM}_{2.5}$ mass measurements by these two personal samplers $\left(\chi^{2}=0.64, p\right.$-value 0.42$)$.

As shown in Table 2, both methods overestimated $\mathrm{PM}_{2.5}$ mass compared to the FRM: the PPOMS by $9 \%$ (slope $=1.09, \mathrm{R}^{2}=0.95$ when forced through the origin), and the HPEM by $18 \%$ (slope $1.18, R^{2}=0.73$ when forced through the origin). Our results with the HPEM are consistent with those of Williams (31), who found that the PEM (similar in design to the HPEM) had a positive mass concentration bias up to $18 \%$, relative to the FRM. 


\section{Quartz Filter "Positive" Artifact Elimination.}

A primary objective of the PPOMS development is elimination of the positive OC artifact that has been observed when using the single quartz filter method was used in indoor and ambient particulate monitoring. To evaluate the ability of the PPOMS to reduce this artifact, a special indoor experiment was conducted at two houses in greater Seattle during May 2001. At these locations, the PPOMS was compared to a denuder sampler, the double-filter method, and the conventional single-filter method. Figure 4 shows the results.

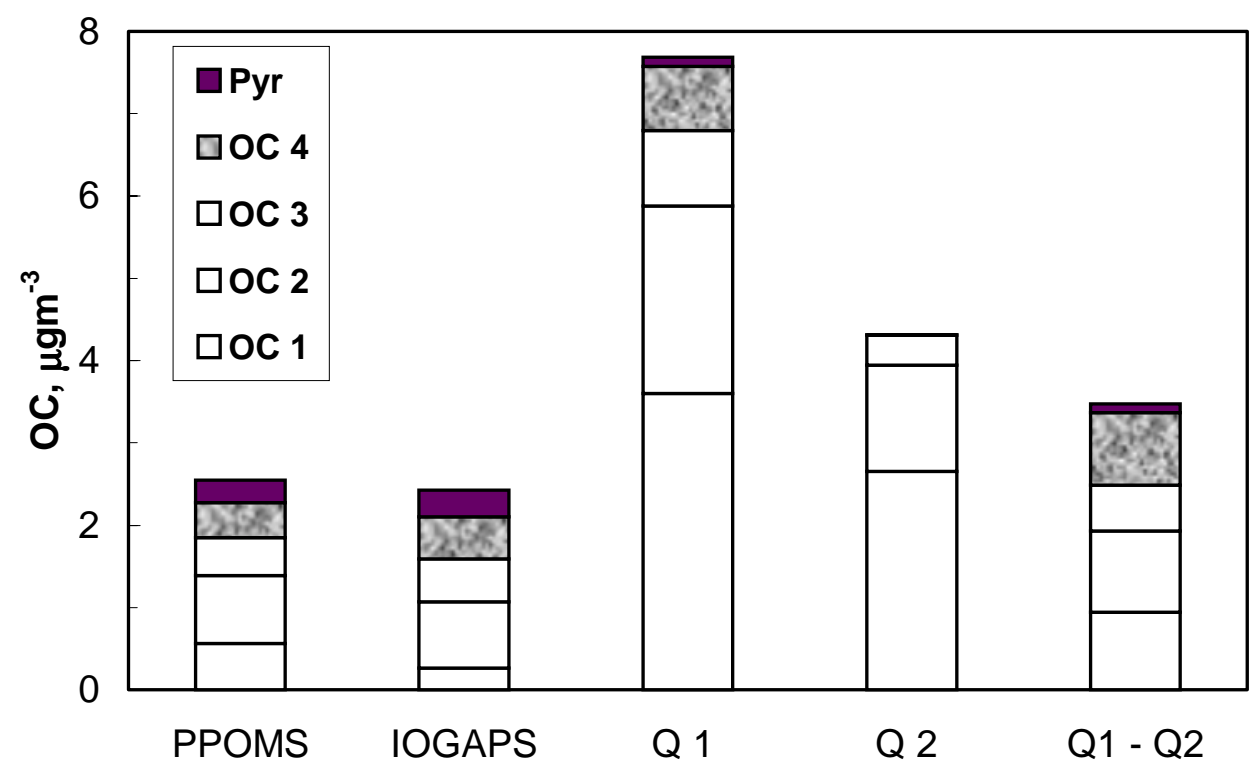

Figure 4. Comparison of indoor organic carbon fractions from different samplers.

The average indoor OC concentration data are shown in Table 3. Indoor OC determined from the PPOMS agreed well with that from the IOGAPS, but both were less than either the single-filter or the double-filter method. The nonparametric Wilcoxon rank sum test indicated no significant difference between the PPOMS and IOGAPS methods for indoor OC measurements $\left(\chi^{2}=0.33\right.$, p-value 0.42$)$. Concentrations of particulate EC from the various sampling methods were all in the same range.

The average $\mathrm{OC}$ in $\mathrm{PM}_{2.5}$ collected on the single quartz filters was 3 times the average $\mathrm{OC}$ determined from quartz filters in the PPOMS or the IOGAPS. Moreover, the average concentration of

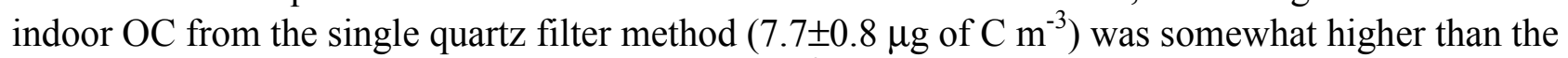
average $\mathrm{PM}_{2.5}$ mass concentration $\left(7.3 \pm 2.3 \mu \mathrm{g} \mathrm{C} \mathrm{m}^{-3}\right)$ from the Teflon filters in the collocated Harvard Impactor.

The good agreement between the PPOMS and IOGAPS (Figure 4) shows that, even for indoor $\mathrm{PM}_{2.5}$ sampling, the PPOMS can eliminate the quartz filter positive artifact just as well as the IOGAPS can. Moreover, the same activated carbon foam was used during the entire 10-day experiment without any apparent degradation in denuding capacity. The high capacity and continuous-use capability are advantages of activated carbon. 
Table 3. Average indoor OC and $\mathrm{EC}( \pm \sigma, \mu \mathrm{g} \mathrm{C} \mathrm{m}-3)$ determined from different samplers, with the range shown in parentheses. PM2.5 mass averaged 7.3 $\pm 2.3 \square \mathrm{m}-3$.

\begin{tabular}{llllll}
\hline Samplers: & $\mathrm{n}$ & PPOMS & IOGAPS & Single $^{\mathrm{a}}$ & Double $^{\mathrm{b}}$ \\
\hline $\mathrm{OC}^{\mathrm{c}}$ & 9 & $\begin{array}{l}2.5 \pm 0.4 \\
(1.9-3.2)\end{array}$ & $\begin{array}{l}2.4 \pm 1.0 \\
(1.6-3.4)^{d}\end{array}$ & $\begin{array}{l}7.7 \pm 0.8 \\
(6.6-9.3)\end{array}$ & $\begin{array}{l}(2.3 \pm-6.3) \\
\end{array}$ \\
& & & & \\
\hline $\mathrm{EC}$ & 9 & $\begin{array}{l}0.1 \pm 0.2 \\
(0.0-0.5)\end{array}$ & $\begin{array}{l}0.1 \pm 0.1 \\
(0.0-0.3)^{d}\end{array}$ & $\begin{array}{l}0.1 \pm 0.2 \\
(-0.2-0.4)\end{array}$ & $(-0.0-0.4)$
\end{tabular}

${ }^{a}$ Data from the first quartz filter in Harvard Impactor.

${ }^{b}$ Data show the difference between the first and second filters in the HI.

${ }^{\mathrm{c}} \mathrm{OC}=\mathrm{OC} 1+\mathrm{OC} 2+\mathrm{OC} 3+\mathrm{OC} 4+\mathrm{OC} 5$

${ }^{\mathrm{d}}$ Number of samples $=8$.

Since it has been shown previously that the XAD-coated denuder in the IOGAPS eliminates the positive artifact for particulate sampling onto a quartz filter $(32,33)$, we infer that the high indoor OC concentrations measured by the single-filter method were the result of adsorption of gas-phase SVOC onto the quartz filters during sampling. The detailed TOT temperature profiles are also consistent with the hypothesis that the $\mathrm{OC}$ concentrations found with the single quartz filter method were due to a positive artifact. Figure 4 compares the OC in samples from the PPOMS, IOGAPS, and single and double filters for each fraction. There were significant differences between the samplers in the lowtemperature $\mathrm{OC}$ fractions. The average $\mathrm{OC} 1$ determined from the single-filter method was $3.0 \mu \mathrm{g}$ of $\mathrm{C}$ $\mathrm{m}^{-3}$ higher than that determined from the PPOMS, and $3.3 \mu \mathrm{g}$ of $\mathrm{C} \mathrm{m}^{-3}$ higher than that determined from the IOGAPS. The OC2 on the single-filter was $1.5 \mu \mathrm{g} \mathrm{C} \mathrm{m}^{-3}$ higher than that collected by the PPOMS and IOGAPS. In comparison, the higher temperature fractions OC3 - OC5 collected by the single filter had only $0.6 \mu \mathrm{g} \mathrm{C} \mathrm{m}^{-3}$ more than those collected by the PPOMS and $0.4 \mu \mathrm{g}$ of $\mathrm{C} \mathrm{m}^{-3}$ more than those collected by the IOGAPS.

Analysis of the backup quartz filter (the second quartz filter in the $\mathrm{HI}_{2.5}$ ) confirmed that the differences in the OC1 and OC2 concentrations between the single- filter method and the denuded samples from the PPOMS or IOGAPS were due to the quartz filter positive artifact. The backup quartz filter only collected gas-phase organic compounds because all particulate organic compounds have already been collected by the first quartz filter $(\sigma)$. Compounds that desorbed from the particles could recondense on the backup filter, but this effect is expected to be small (6). OC1 and OC2 accounted for $95 \%$ of total OC from the second filter, which is consistent with its adsorption of gas-phase semivolatile organic carbon.

There are three limitations to the double-filter method. First, there may be depletion of the organic vapor by the upstream filter, leading the second to underestimate the positive artifact. An additional sampler, in which a quartz filter follows a Teflon filter, can be used to evaluate the front quartz filter positive artifact (6) more accurately. Second, the adsorption characteristics (e.g., surface functional groups, selectivity, hydrophilicity, and capacity) of different quartz filters may be different, leading to errors in correcting for the positive artifact by either the double-filter method or the addition 
of a second sampler that has Teflon and quartz filters (34). Third, the double-filter method would lead to misleading or erroneous results if negative (blow-off) artifacts were large, as seen in some ambient environments with high particle loading. Given these limitations, and propagation of errors in subtraction, it is not surprising that the double-filter results showed more variability than those from the PPOMS or IOGAPS. A recent review by Turpin et al. (35) and work by Mader and Pankow (36) provide further insight about the origin of organic sampling artifacts on quartz filters.

The residence time of particles through the PPOMS foam is $0.03 \mathrm{~s}$, which is short enough to minimize evaporation of SVOC from particles during passage through the carbon foam. However, evaporation of $\mathrm{OC}$ from collected particles has not been measured in this study. Finding a method to estimate the evaporation artifact accurately as OC is still a sampling and analytical challenge. The double filter method is less subject to the evaporation artifact. The results of Lewtas et al. (33) in comparing two denuder and two sorbent-impregnated filter types suggest to us that the evaporation artifact could be assessed more accurately from XQ used in future PPOMS than from XQ in the IOGAPS. The XAD-coated denuders and filters in the IOGAPS are designed for SVOC, and they trap VOC incompletely. The ACF has the advantage of better VOC removal. However we do not yet have any data to test this hypothesis. XQ can be added to the PPOMS, even in the current cassette body, and future validation studies will include XQ or CIF.

\section{Limitations and Need for Further Investigation.}

The PPOMS proof of concept has been established with the limited field studies that are reported here. However, further investigation is needed for thorough evaluation and validation. For example, its collection characteristics as a size-selective inlet need to be established using standard aerosols. The capacity and lifetime of various types of ACF should be evaluated under controlled conditions with challenge SVOC and aerosols, as well as in ambient and indoor air. Additionally, the PPOMS should include a suitable postfilter substrate for determination of the evaporation artifact. A compact, lightweight, inexpensive, convenient, combined size-selective inlet and denuder for fine particulate sampling has been developed that eliminates the positive organic sampling artifact.

\section{ACKNOWLEDGMENTS}

This study was funded by the U.S. Environmental Protection Agency cooperative agreement (\#R82717701) and the NW Center for Particulate Matter and Health (\#R827355010). It has not been subjected to the Agency's peer and policy review and therefore does not necessarily reflect the views of the Agency and no official endorsement should be inferred. Additional support for the thermal-optical transmission carbon analyses was provided from the Washington State University Center for Multiphase Environmental Research and the Mickey Leland National Urban Air Toxics Research Center. ACF was provided by Gerald Ayotte and Zen Kruczkowski of Lewcott Co. and Betty Lin of Macauto Industrial Co., Ltd. The authors appreciate the help of Jim Frost, Sean Lundblad and Joan McMillen of the Washington State Department of Ecology in providing the FRM data and Tim Gould of the University of Washington and Raymond Dod of Lawrence Berkeley National Laboratory for technical assistance. The authors also thank Douglas Lane of Environment Canada for the loan of an IOGAPS for indoor sampling. 


\section{REFERENCES}

1. Lioy, P.J; Daisey, J.M; Atherholt, T.; Bozzelli, J.; Darack, F.; Fisher, R.; Greenberg, A.; Harkov, R.; Kebbekus, B.; Kneip, T.; Kouis, J. J Air Waste Manage. Assoc. 1983, 33, 49-657.

2. Matsumoto, H.; Inoue, K. Arch. Environ. Contam. Toxicol. 1987, 16, 409-416.

3. National Research Council. Research Priorities for Airborne Particulate Matter: II. Evaluating Research Progress and Updating the Portfolio; National Academy Press: Washinton, DC 1999, p. 27-38.

4. Saldiva, P.; Clarke, R.; Coull, B.; Stearns, R.; Lawrence, J.; Murthy, G.; Diaz, E.; Koutrakis, P.; Suh. H.; Tsuda, A.; Godleski, J. Am. J. Respir. Crit. Care Med. 2002, 165, 1610-7.

5. Cui, W.; Machir, J.; Lewis, L.; Eatough, N.L.; Eatough, D.J. Journal of the Air and Waste Management Association 1997, 47, 357-369.

6. Turpin, B.J.; Huntzicker, J.J.; Hering, S.V. Atmos. Environ. 1994, 28, 3061-3071.

7. McDow, S.R.; Huntzicker, J.J. Atmos. Environ, 1990, 24(A), 2563-2571.

8. Appel, B. R.; W. Cheng; Salaymeh, F. Aerosol Sci. Technol., 1989, 10, 2167-2176.

9. Eatough, D.J.; Tang, H.; Cui, W.; Machir, J., Determination of the size distribution and chemical composition of fine particulate semi-volatile organic material in urban environments using diffusion denuder technology, Inhal. Toxicol., 1995, 7, 691-710.

10. Eatough, D.J.; Cui, W. Semi-volatile particulate organic compounds in urban fine particles. in Particulate Matter: Health and Regulatory Issues, VIP-49; Air \& Waste Management Association: Pittsburgh, PA. 1996; pp. 320-331.

11. Cui, W.; Eatough, D.J.; Eatough, N. Journal of the Air and Waste Management Association, 1998,48, 1024-1037.

12. Tang, H.; Lewis, E.A.; Eatough, D.J.; Burton, R.M.; Farber, R.J. Atmos. Environ. 1994, 28, 939947.

13. John, W.; Wall, S. M.; Ondo, J. L. Atmos. Environ. 1988, 22, 1627-1636.

14. Claiborn, C.S.; Pang, Y.; Gundel, L.A.; Larson, T.; Liu, L.-J. S. Comparison of indoor, outdoor, and personal fine particulate organic and elemental carbon measurements in Seattle, Annual Meeting of the American Association for Aerosol Research, Portland, OR, October 2001.

15. Landis, M.S.; Norris, G.A.; Williams, R.W.; Weinstein, J.P. Atmos. Environ. 2001, 35, 6511-6524.

16. Eatough, D.J.; Wadsworth, A.; Eatough, D.A.; Crawford, J.W.; Hansen, L.D.; Lewis, E.A. Atmos. Environ. 1993, 27A, 1213-1219.

17. Gundel, L.A., Lee, V.C.; Mahanama, K.R.R.; Stevens, R.K.; Daisey, J.M., Atmos. Environ. 1995, 29,1719-1733.

18. Gundel, L. A.; Lane, D. A. J. Aerosol Sci. 1998, 29: (Suppl. 1.), s341-s342.

19. Gundel, L.A; Lane, D.A. Sorbent-coated diffusion denuders for direct measurement of gas/particle partitioning by semi-volatile organic compounds. In Advances in Environmental, Industrial and Process Control Technologies. Vol. 2. Gas and Particle Partition Measurements of Atmospheric Organic Compounds; Lane, D.A., Ed.; (Newark, Gordon and Breach): Reading, U.K., 1999; pp 287332.

Submitted to ES\&T May 8, 2002;

Accepted August 27, 2002 
20. Fitz, D.R. Aerosol. Sci. Technol. 1990, 12, 142-148.

21. Kenny, L.C., Bowry, A.; Crook, B.; Stancliffe, J.D. Field testing of a personal size-selective bioaerosol sampler, Am. Occup. Hyg. 1999, 43, 393-404.

22. Kenny, L.C.; Stancliffe, J.D.; Crook, B.; Staff, S.; Griffiths, W.D.; Stewart, I.W.; Futter, S.J. Am. Ind. Hyg. Assoc. J. 1998, 59, 831-841.

23. Buckley, T. J.; Waldman, J. M.; Freeman, N. G.; Lioy; P. J.; Marple, V. A; Turner, W. A. Aerosol Sci. Technol. 1991, 14, 380-387.

24. Gundel, L. A. Standard Operating Procedures for Coating Annular Denuders with XAD-4 Resin for the US EPA Chemical Speciation Program, 1999; LBNL PUB-3143.

25. Allen, R; Box, M.; Larson, T.; Liu, L.-J.S. J. Air \& Waste Manage. Assoc. 2001, 51, 1651-1653.

26. Birch, M. E.; Cary, R. A. Aerosol Sci. Technol. 1996, 25, 221-241.

27. Vincent, J.H.; Aitken, R.J; Mark, D. J. Aerosol Sci., 1993, 24, 929.

28. Chen, C.; Lai, C.; Shih, T.; Yeh, W. Am. Ind. Hyg. Assoc. J. 1998, 59, 766-773.

29. Sioutas, C.; Chang, M.; Kim, S.; Koutrakis, P.; Ferguson, S. J. Aerosol Sci., 1999, 30, 693-707.

30. Demokritou, P.; Kavouras, I. G.; Ferguson, S. T.; Koutrakis, P., Aerosol Sci. Technol. 2001, 35 , $741-752$

31. Williams, R.; Suggs, J.; Rodes, C.; Lawless, P.; Zweidinger, R.; Kwok, R.; Creason, J.; Sheldon, L. J. Exposure Anal. Environ. Epidemiol. 2000, 10, 497-505.

32. Pang, Y., Measurements of particulate semi-volatile material, Ph.D Dissertation, 2000, Brigham Young University, 2000.

33. Lewtas, J., Pang, Y., Booth, D., Reimer, S., Eatough, D., and Gundel, L., Comparison of sampling methods for semi-volatile organic carbon (SVOC) associated with $\mathrm{PM}_{2.5}$ Aerosol Sci. \& Technol. 2001, 34, 9-22.

34. Kirchstetter, T.; Corrigon, C.; Novakov, T. Atmos. Environ. 2001, 35A, 1663-1671.

35. Turpin, B.J., Saxena, P.; Andrews, E. Atmos Environ. 2000, 34, 2983-3013.

36. Mader, B.T. and Pankow, J.F, Gas/solid partitioning of semivolatile organic compounds (SOCs) to air filters. 2. Partitioning of polychlorinated dibenzodioxins, polychlorinated dibenzofurans and polycyclic aromatic hydrocarbons to quartz fiber filters, Atmos Environ. 2001, 35, 1217-1223. 